\title{
Radiological profiles of nasopharyngeal anatomy as seen in computed tomography scans of normal patients undergoing brain scans for other neurological problems in Konkani population
}

\author{
Santhosh Kumar Rajamani ${ }^{1}$, Nayanna Karodpati ${ }^{2} *$, Dilesh A. Mogre ${ }^{1}$, Rashmi Prashant ${ }^{2}$
}

${ }^{1}$ Department of ENT, B.K.L Walawalkar Rural Medical College, Chiplun, Ratnagiri, Maharashtra, India

${ }^{2}$ Department of ENT, D Y Patil Medical College, Pune, Maharashtra, India

Received: 28 August 2019

Revised: 05 October 2019

Accepted: 07 October 2019

\section{*Correspondence:}

Dr. Nayanna Karodpati,

E-mail: karodpati13@yahoo.co.in

Copyright: () the author(s), publisher and licensee Medip Academy. This is an open-access article distributed under the terms of the Creative Commons Attribution Non-Commercial License, which permits unrestricted non-commercial use, distribution, and reproduction in any medium, provided the original work is properly cited.

\begin{abstract}
Background: Nasopharyngeal carcinoma arises from interactions between underlying genetic and racial predilection and variety environmental factors. It is locally aggressive and presents with occult cervical nodal metastasis. A thorough understanding of radiological regional anatomy of the nasopharynx in Indians particularly Konkani population is important for early detection of nasopharyngeal carcinoma.

Methods: Routine computed tomography of brain, head and neck for other neurological problems like stroke clearly delineates the loco-regional anatomy of the nasopharynx. Computed tomography (CT) images stored in the computer system were studied to delineate the normal loco-regional anatomy of nasopharynx with special reference to anatomical structure of fossa of Rosenmueller and to find out the normal dimensions of nasopharynx in Konkani population. Nasopharyngeal carcinoma is a hidden and cryptic killer with relatively higher incidence among young population. To develop a local screening CT program for earlier detection of this occult malignancy was another purpose of this endeavour.

Results: Internal carotid artery lies at the depth of around 1 to $1.7 \mathrm{~cm}$ from floor of lateral pharyngeal recess (fossa of rosenmuller); this figure has to be borne in mind while doing invasive procedures of nasopharynx like biopsies and adenoidectomy.

Conclusions: Posterior pharyngeal wall thickness of more than $2.4 \mathrm{~cm}$ and adenoid mass extending to posterior margin of the medial pterygoid plate is suspicious of malignancy. A screening protocol of CT nasopharynx has been suggested as a fruit of this endeavour.
\end{abstract}

Keywords: Multidetector computed tomography, Nasopharynx, Anatomy, Nasopharyngeal carcinoma

\section{INTRODUCTION}

Nasopharynx in the pre-endoscopic era was termed as the "Pandora's box" of Otorhinolaryngology due to inaccessibility and poor visualization. Most Nasopharyngeal diseases have been traditionally been under diagnosed. There are a variety of conditions like acute otitis media, nasopharyngeal carcinoma, choanal atresia, obstructive sleep apnoea, cleft palate, dental overbite/malocclusion, anosmia and cleft palate which are associated with the nasopharyngeal dimensions. ${ }^{1}$ In this research we explore the anatomy of the nasopharynx using radiological images.

The aims and objectives of this study were to delineate the normal loco-regional anatomy of nasopharynx with special reference to anatomical structure of fossa of 
Rosenmueller and further, to chart out the normal dimensions of nasopharynx in Konkani population.

Nasopharynx has been studied using a variety of techniques like dye injection, rhinomanometry with the pressure-flow technique, X-rays and magnetic resonance imaging (MRI). ${ }^{2}$ High arched palate and deviated nasal septum as a consequence of adenoid hypertrophy are described in the spectrum of adenoid facies and chronic mouth breathing. ${ }^{3}$ Hypo and hypernasality of speech are functional problems encountered in ENT clinic due to decreased and increased nasal resonance respectively. Up to $60 \%$ of patients with cleft lip and palate suffer from hyper-nasality and compromised naso-pharyngeal airway, with resultant mouth-breathing and adverse effect on the craniofacial development. ${ }^{4}$ This adenoidal hypertrophy causes nasopharyngeal airway obstruction which leads mouth breathing, as a result of nasal obstruction. ${ }^{5}$ This has adverse effects on the normal naso-maxillary development. The correlation between nasopharyngeal dimensions size and the adenoid pad is of vital importance. ${ }^{6} \mathrm{CT}$ is available in our rural hospital and provides vital information about the extent and character of mass lesions. In known tumours like juvenile nasopharyngeal angiofibroma of nasopharynx, CT is used to determine the extent of bony invasion, the compression and invasion of the tumour into vital structures like Internal carotid artery and brain, and the involvement of loco-regional lymph nodes like retro-pharyngeal and para-pharyngeal lymph nodes. Additional wealth of information can be obtained by using intravenous contrast because enlarged lymph node may be difficult to differentiate from the surrounding soft-tissue especially inflamed tissues. Renal failure and contrast allergy are contraindications to the use of contrast. ${ }^{7}$

\section{METHODS}

\section{Study design}

This was a cross sectional descriptive epidemiological, non-randomized trial, unicentric type of study in hospital setting to delineate the loco regional and radiological anatomy of nasopharynx in Konkani population.

\section{Study place and duration}

Study place was carried out in Department of E.N.T, B.K.L Walawalkar Rural Medical College Hospital from 25 November 2018 to 24 March 2019 (3 months 27 days).

\section{Selection criteria of the patients}

Routine computed tomography of brain, head and neck for other neurological problems like stroke clearly delineates the loco-regional anatomy of the nasopharynx. Extremes of ages (>60 years and <14 years of age were excluded from this study). Existing head and neck pathology cases were also excluded from this study.

\section{Procedure}

A wealth of such images data is available on the Computer database of our institute. This was utilized and a reasonable picture of radio-anatomy of nasopharynx in Konkani population can be inferred at no cost or risk to the patients. Nasopharyngeal carcinoma is a hidden and cryptic killer with relatively higher incidence among young population. To develop a local screening computed tomography (CT) program for earlier detection of this occult malignancy was another purpose of this endeavour.

CT scan of nasopharynx was performed with a maximum slice thickness of $5 \mathrm{~mm}$. If any pathology was detected thinner slices were ordered to delineate the extent of pathology. As a standard practice, if contrast was found necessary, a contrast bolus of $100 \mathrm{ml}$ was given intravenously after test dose with a time-delay of 1 minute. Any patient with middle ear effusion was diligently evaluated for mass in the nasopharynx that could lead to Eustachian tube dysfunction, causing an effusion.

\section{Ethics committee approval}

Ethical guidelines of the institutional research committee were followed and committee's formal approval was obtained before embarking on this research. Additional informed consent was obtained from all individual participants for whom any identifying information is included in this article.

\section{Methodology of CT evaluation of normal nasopharyngeal anatomy}

\section{Study population}

We chose 100 normal patients who did not have any findings physical examination of the nasopharynx and no clinical suspicion of nasopharyngeal disease. These patients underwent CT of brain for reasons unrelated to the nasopharynx. All of the studies were done on General Electric Company's Brivo CT385, 16 slices which is available in our hospital. Study was carried out from 25 November 2018 to 24 March 2019. C.T images on computer records database were accessed from 01 January 2016 to 15 March 2019. Standard axial scans were studied at $5 \mathrm{~mm}$ intervals with the infraorbial, Reid's meatal line perpendicular to the plane of the table. Current for such a study was set to $10 \mathrm{~mA}$, slice thickness 1.25 and resolution at $1024 \times 512$ pixels. Patients are routinely asked to open their mouth widely or do a Valsalva manoeuvre, the resulting air distension of nasopharynx is helpful in air-soft tissue contrast outlining of the eustachian tubes and lateral pharyngeal recesses (fossa of Rosenmuller). 
Clinical characteristics of the study participants

Dimensions of nasopharynx were calculated by the following protocol, anterio-posterior length of nasopharynx was calculated at the maximum distance between the anterior and posterior walls mucosal edges in sagittal images. The width and height of nasopharynx measured in the coronal and axial images. ${ }^{8}$ The measure of anteroposterior nasopharyngeal dimension was measured as the distance between the posterior hard palate edge and the superior pharyngeal constrictor muscle. The greatest distance between mucosa on left and right medial pterygoid plates was measured and quantified as width of the nasopharynx.

One quick way of identification of fundus of lateral pharyngeal recess (fossa of Rosenmuller) in axial cuts was to look for dumbbell like appearance of the condyle and coronoid process of the mandible, separated by the mandible notch. This is a unique finding of this study and named as "Dumbbell sign of fundus" of lateral pharyngeal recess (fundus appears like a dot or a bubble). This was observed in almost all axial images as depicted in the CT image.

Oon's method of measurement of soft-tissue thickness of the posterior wall of nasopharynx was used. This method was used in X-ray films but can be extrapolated with increased sensitivity for CT images. The soft-tissue thickness of the posterior wall of nasopharynx is measured from a line connecting posterior edge of the soft palate to the anterior lip of the foramen magnum (Basion). ${ }^{9}$

\section{Bio-statistical analysis}

All the bio-statistical analysis was done with done using the PAST Paleontological statistics software package for education and data analysis package. A confidence interval of $95 \%(p=0.05)$ was setup for the entire Hypothesis tested in this study. Analysis of variance test (ANOVA), Pearson's Chi-square test and linear regression modelling were employed in order to compare the observed traits according to demographic and clinical characteristics. When condition of normality of data was doubtful, we used a nonparametric test to compare two samples such as the Mann-Whitney. ${ }^{10}$

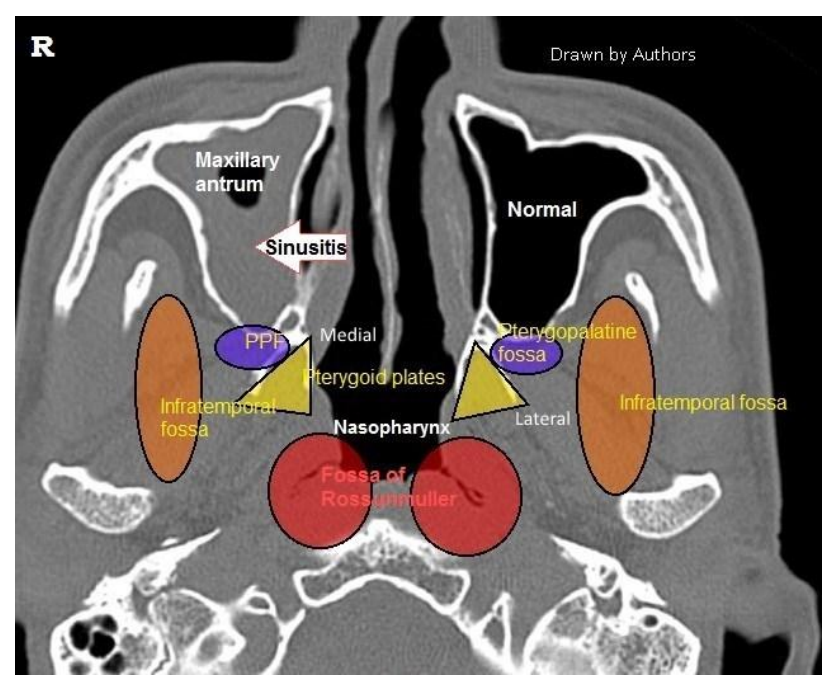

Figure 1: Normal regional anatomy of the nasopharynx with lateral pharyngeal recess (fossa of Rosenmuller) and showing adenexal structures like pterygopalatine fossa, infra-temporal fossa; this patient has right maxillary sinusitis.

\section{RESULTS}

The following measurement and observation were made in the CT images of the selected cases. Visible air in the Eustachian tube is normal and was seen in axial cuts during quite respiration to maximum $4 \mathrm{~mm}$ was seen only in 8 cases. This is not of any clinical significance.

Mean age of patient included in this study was $53.324 \pm 7.31$ years, the median age was 55 years. There is a bias towards elderly population as these are more likely to get a CT scan of the brain. 63 males and 37 females were included in this study. Mean depth of nasopharynx at the level of Dumbbell's sign or fossa of Rosenmuller was found to be $20.3894 \pm 1.44 \mathrm{~mm}$, length (width) of nasopharynx was found to be $26.93706 \pm 1.922 \mathrm{~mm}$ and height of nasopharynx was detected to be $20.176 \pm 0.650$ $\mathrm{mm}$. The depth and width were not statistically significant from the average mean of population. Konkani population has similar depth and width dimensions, while height dimension is statistically different from world average (at $p$ value of $1.206 \times 10^{-20}<<0.05$ ).

Table 1: Baseline demographic characteristics.

\begin{tabular}{|ll|}
\hline Name of variable and comment & Observed value \\
\hline $\begin{array}{l}\text { Age of patients included in this study } \\
\text { (Statistically normalized for any age bias due to CT } \\
\text { scan of brain more common in elderly) }\end{array}$ & $\begin{array}{l}\text { Mean age 53.324 } \\
\text { Kurtosis }-1.15048 \\
\text { Median age 55 years }\end{array}$ \\
\hline Sex of the patients & 63 males and 37 females \\
\hline $\begin{array}{l}\text { Urban versus rural population from our medical } \\
\text { records }\end{array}$ & $88 \%$ rural Konkani populations \\
\hline Level of education & $\begin{array}{l}3 \% \text { post graduate, } 7 \% \text { college graduate, 13\% high school, } \\
67 \% \text { illiterate population }\end{array}$ \\
\hline Language of communication & $90 \%$ Marathi, 6\% Konkani, 4\% Hindi and others \\
\hline
\end{tabular}


Table 2: Observed computed tomographic data for normal nasopharynx.

\begin{tabular}{|ll|}
\hline $\begin{array}{l}\text { Name of variable and comment } \\
\begin{array}{l}\text { Anteroposterior (depth) dimension of nasopharynx at the level of Dumbbell's } \\
\text { sign or fossa of Rosenmuller (mean data is available in literature) }\end{array}\end{array}$ & Average $20.3894 \pm 1.44 \mathrm{~mm}$ \\
\hline $\begin{array}{l}\text { Lateral dimension (width) of nasopharynx at the level of Dumbbell's sign or } \\
\text { fossa of Rosenmuller }\end{array}$ & Average $26.93706 \pm 1.922 \mathrm{~mm}$ \\
\hline Height dimension of nasopharynx at the same level in coronal CT images & Average $20.176 \pm 0.650 \mathrm{~mm}$ \\
\hline Dimension of right lateral pharyngeal recess (fossa of Rosenmuller) & Average $11.156 \pm 1.04 \mathrm{~mm}$ \\
\hline Dimension of left lateral pharyngeal recess (fossa of Rosenmuller) & Average $10.367 \pm 1.02 \mathrm{~mm}$ \\
\hline $\begin{array}{l}\text { Depth of right internal carotid artery from floor of the right lateral } \\
\text { pharyngeal recess (fossa of Rosenmuller) }\end{array}$ & Average $9.883 \pm 0.82 \mathrm{~mm}$ \\
\hline $\begin{array}{l}\text { Depth of left internal carotid artery from floor of the right lateral pharyngeal } \\
\text { recess (fossa of Rosenmuller) }\end{array}$ & Average $9.735 \pm 0.72 \mathrm{~mm}$ \\
\hline Mucosal thickness of nasopharyngeal vault posterior wall & Average $17.31 \pm 3.104 \mathrm{~mm}$ \\
\hline
\end{tabular}

Table 3: Outcome with bio-statistical inferences from our data.

\begin{tabular}{|c|c|c|}
\hline Name of variable and comment & $\begin{array}{l}\text { Biostatistical analysis } \\
\text { Alpha level at } \mathrm{p}=0.05\end{array}$ & \\
\hline $\begin{array}{l}\text { Anteroposterior (depth) dimension of } \\
\text { nasopharynx at the level of } \\
\text { Dumbbell's sign or fossa of } \\
\text { Rosenmuller (mean data is available } \\
\text { in literature) }\end{array}$ & $\begin{array}{l}\text { One sample t test (Given mean } 21.80714) \\
\text { Calculated } p=0.06687>0.05 \\
\text { Not statistically significant }\end{array}$ & \\
\hline $\begin{array}{l}\text { Lateral dimension (width) of } \\
\text { nasopharynx at the level of } \\
\text { Dumbbell's sign or fossa of } \\
\text { Rosenmuller }\end{array}$ & $\begin{array}{l}\text { One sample t test }(\text { Given mean } 25.31951) \\
\text { Calculated } p=0.1086>0.05 \\
\text { Not statistically significant }\end{array}$ & \\
\hline $\begin{array}{l}\text { Height dimension of nasopharynx at } \\
\text { the same level in coronal CT images }\end{array}$ & $\begin{array}{l}\text { One sample t test (Given mean 19.4619) } \\
\text { Calculated } p=2.615 \times 10^{-24}<<0.05 \\
\text { Statistically significant }\end{array}$ & \\
\hline $\begin{array}{l}\text { Dimension of right lateral pharyngeal } \\
\text { recess (fossa of Rosenmuller) }\end{array}$ & $\begin{array}{l}\text { One sample t test } \\
\text { Calculated } \mathrm{p}=1.206 \times 10^{-20}<<0.05 \\
\text { Statistically significant }\end{array}$ & \multirow{2}{*}{$\begin{array}{l}\text { Right and Left data two } \\
\text { independent sample } \mathrm{F} \text { and } \mathrm{t} \\
\text { tests } \mathrm{p}=0.29239>0.05 \\
\text { No statistical difference } \\
\text { between right and left side } \\
\text { measurements }\end{array}$} \\
\hline $\begin{array}{l}\text { Dimension of left lateral pharyngeal } \\
\text { recess (fossa of Rosenmuller) }\end{array}$ & $\begin{array}{l}\text { One sample t test } \\
\text { Calculated } \mathrm{p}=5.58 \times 10^{-20}<<0.05 \\
\text { Statistically significant }\end{array}$ & \\
\hline $\begin{array}{l}\text { Depth of right internal carotid artery } \\
\text { from floor of the right lateral } \\
\text { pharyngeal recess (fossa of } \\
\text { Rosenmuller) }\end{array}$ & $\begin{array}{l}\text { One sample t test } \\
\text { Calculated } p=2.981 \times 10^{-22}<<0.05 \\
\text { Statistically significant }\end{array}$ & \multirow{2}{*}{$\begin{array}{l}\text { Right and left data two } \\
\text { independent sample } \mathrm{F} \text { and } \mathrm{t} \\
\text { tests } \mathrm{p}=0.79142>0.05 \\
\text { No statistical difference } \\
\text { between right and left side } \\
\text { measurements }\end{array}$} \\
\hline $\begin{array}{l}\text { Depth of left internal carotid artery } \\
\text { from floor of the right lateral } \\
\text { pharyngeal recess (fossa of } \\
\text { Rosenmuller) }\end{array}$ & $\begin{array}{l}\text { One sample } \mathrm{t} \text { test } \mathrm{t}=26.46 \\
\text { Calculated } \mathrm{p}=8.503 \times 10^{-24}<<0.05 \\
\text { Statistically significant }\end{array}$ & \\
\hline $\begin{array}{l}\text { Mucosal thickness of nasopharyngeal } \\
\text { vault posterior wall }\end{array}$ & $\begin{array}{l}\text { One sample } \mathrm{t} \text { test } \mathrm{t}=14.2 \\
\text { Calculated } \mathrm{p}=1.288 \times 10^{-15}<<0.05 \\
\text { Statistically significant }\end{array}$ & \\
\hline
\end{tabular}

Depth of right or left internal carotid artery from floor of the lateral pharyngeal recess was found to be $9.883 \pm 0.82$ $\mathrm{mm}$ and $9.735 \pm 0.72 \mathrm{~mm}$ respectively. This is surgically important as injury to internal carotid is fatal in procedures of nasopharynx like biopsy or adenoidectomy. Mucosal thickness of posterior wall is clinically important for detection of early, especially sub-mucosal malignancy, which may appear as a localized area of thickness. This study found that the average value of mucosal thickness was average $17.31 \pm 3.104 \mathrm{~mm}$ on the posterior wall of nasopharyngeal vault. It can be inferred that upper limit of mucosal thickening is $20.414 \mathrm{~mm}$ in the posterior pharyngeal wall; any value beyond this is suspicious. 


\section{DISCUSSION}

Normal nasopharynx is described as an inverted J-shaped muscular-aponeurosis hung from the central regions of the cranial base. ${ }^{13}$ The roof of the nasopharynx is limited by basisphenoid, posterior-inferior by the bony clivus. Anteriorly it continues as nasal cavity, and inferiorly the soft-palate. C1-C2 vertebral disc is the radiological boundary between the nasopharynx and oropharynx. Roof of nasopharyngeal has the foramen lacerum through which the principal skull base invasion of nasopharyngeal carcinoma occurs.

The pharyngobasilar fascia which is the tough aponeurosis that extends upwards from the superior constrictor to medial pterygoid plate and skull base. This fascia is responsible for structural integrity of the nasopharynx and resists invasion by tumour. Pharyngobasilar fascia separates superficial muscle planes from deeper muscle planes. Superior constrictor muscle is attached to the (=basal tubercle) pharyngeal tubercle of the basiocciput bone. Sinus of Morgagni is a defect in the fascia for entry of Eustachian tube and Levator veli palatine. Torus tubarius or tubal elevation is an inverted " $J$ " shaped elevation in the nasopharynx caused by the cartilaginous end of the Eustachian tube. This appears more slightly radio-dense in C.T images than surrounding soft tissue due to its calcium content. The Eustachian tube orifice is trumpet-shaped and seen anterior to torus tubarius on axial images. Levator palati muscle is the major contributor to muscular soft tissue planes of nasopharynx. Passavant's muscular ridge is seen U-shaped sub-mucosal density about $1.5 \mathrm{~cm}$ below the torus tubarius, these muscles act as a sphincter during swallowing closing off nasopharynx to prevent nasal regurgitation of food.

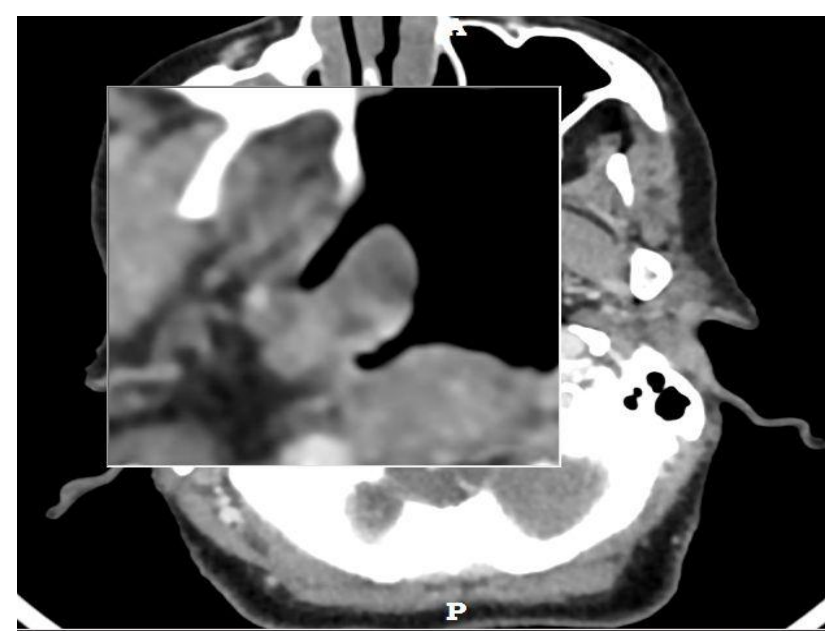

Figure 2: A normal right side torus tubarius; the radio-dense nature of torus tubarius in CT images than surrounding soft tissue due to its calcium content.

Normal loco-anatomy of lateral pharyngeal recess (fossa of Rosenmuller) observed.

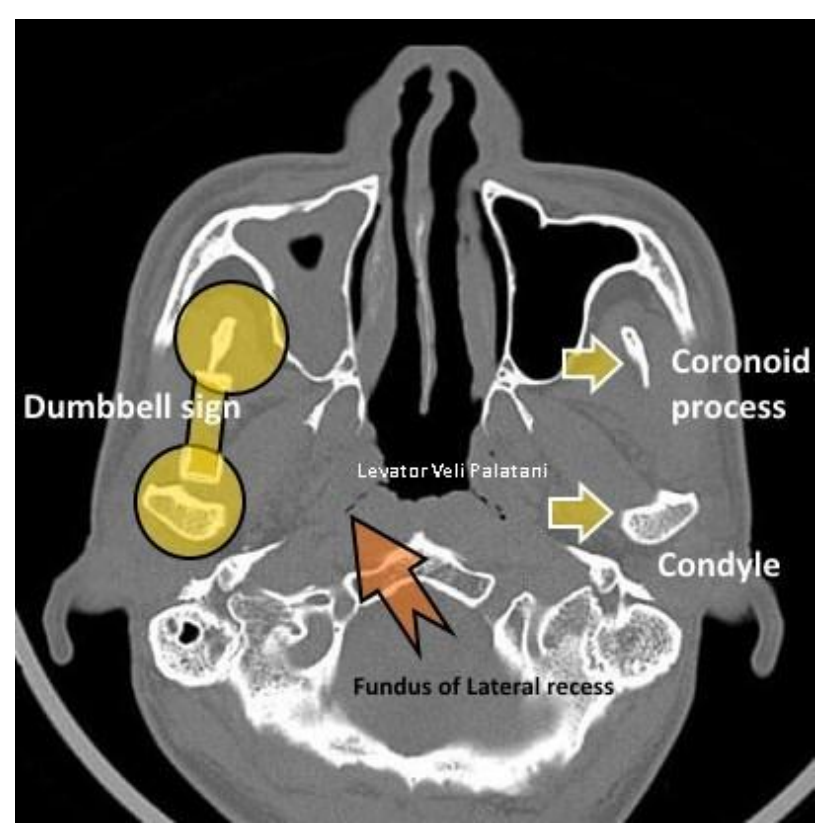

Figure 3: Dumbbell sign of fundus of lateral pharyngeal recess; a quick way of identification of fundus of lateral pharyngeal recess (fossa of Rosenmuller) in axial cuts was to look for Dumbbell like appearance of the condyle and coronoid process of the mandible, separated by the mandibular notch.

The lateral pharyngeal recess (fossa of Rosenmuller) is seen posterior to the torus tubarius in axial cuts. Some degree of asymmetry of lateral pharyngeal recess is normal in healthy individuals. Fossa of Rosenmuller is thought to be formed due mucosa reflection over the Longus colli muscle. Invasion of Longus colli muscle or Levator palati muscle is a sign of malignancy. The shape and depth of the fossa of Rosenmuller is dependent on muscle bulk and mucosal thickness. In elderly the loss of muscle mass results in wide and shallow fossa adding to the needed contrast for evaluation of growths that arise in this region.

Parapharyngeal space which lies in the lateral relation of nasopharynx, is a potential area for invasion or expansion of tumours of this region. Obliteration of the normal fat pads is sign of tumour invasion into these adjacent area Parapharyngeal space or pterygopalatine fossa. ${ }^{14}$ Retropharyngeal nodes which are the first echelon nodes which drain the Nasopharynx are clinically inaccessible. They were seen in few cases as discrete 3-5 mm nodes. ${ }^{15}$ Direct extension sphenoid sinus and infra-temporal fossa is also seen.

Adenoid hypertrophy adenoids grow and reach a maximum size by 5 years of age and by late 30 years should have totally disappeared. After 10 years of age, it is highly uncommon for the adenoids to reach up to the posterior margin of the bony medial pterygoid plate. If such a swelling is visualized on CT scan of an elderly patient further investigation to rule out nasopharyngeal carcinoma is definitely indicated. ${ }^{16}$ 


\section{Nasopharyngeal carcinoma}

Nasopharyngeal carcinoma appears iso-dense to muscle on non-enhanced CT image. There is minimal tumour enhancement is often seen following intravenous contrast. The earliest radiological manifestation of nasopharyngeal carcinoma is an increase in the width of the soft tissue of the wall of nasopharyngeal vault. Our research has delineated the normal soft tissue mucosal wall thickness in Konkani population at a 17.31 \pm 3.104 $\mathrm{mm}$. In previous studies in literature the soft tissue mucosal wall follows the contours of the underlying bone and pre-vertebral muscles especially longus colli and has a thickness that rarely exceeds $1.5 \mathrm{~cm} .{ }^{17}$ This nominative data can be used for screening populations for this occult malignancy. This data is unique for population of this region (Northern-west coast of India) of country and appears first time in literature.

Table 4: Screening for nasopharyngeal growths in Konkani population- Dervan protocol.

\begin{tabular}{|c|c|}
\hline Component & Criteria for normalcy in Konkani population \\
\hline $\begin{array}{l}\text { Soft tissue mucosal wall thickness in Konkani } \\
\text { population on axial CT scan as measured at }\end{array}$ & $\begin{array}{l}\text { Upper limit of mucosal thickening } 20.414 \mathrm{~mm} \text { in the } \\
\text { posterior pharyngeal wall }\end{array}$ \\
\hline $\begin{array}{l}\text { Adenoidal mass to extend up to the posterior margin of } \\
\text { the medial pterygoid plate }\end{array}$ & Suspicious mass in nasopharynx \\
\hline $\begin{array}{l}\text { CT rescan with a "pinched nose" modified Valsalva } \\
\text { manoeuvre or with mouth widely open (to show the } \\
\text { pliability of normal lymphoid tissue) }\end{array}$ & Change in findings \\
\hline $\begin{array}{l}\text { Contour of soft tissue mucosal wall and deep muscle } \\
\text { planes }\end{array}$ & $\begin{array}{l}\text { Follows the contour, altered, does not follow the contour } \\
\text { mild alteration of contour }\end{array}$ \\
\hline Erosion of structures & $\begin{array}{l}\text { Pterygoid plates, clinoid process, clivus, foramen lacerum } \\
\text { especially cartilage in the inferior part; erosion of greater } \\
\text { sphenoid wing }\end{array}$ \\
\hline Lymphatic spread & Lateral or medial retropharyngeal lymph nodes \\
\hline
\end{tabular}

The validity, sensitivity and specificity of this protocol have to be validated by further studies in this region and will be subject of subsequent paper.

Mean depth of nasopharynx at the level of or fossa of Rosenmuller was found to be $20.3894 \pm 1.44 \mathrm{~mm}$, length (width) of nasopharynx was found to be $26.93706 \pm 1.922$ $\mathrm{mm}$ and height of nasopharynx was detected to be $20.176 \pm 0.650 \mathrm{~mm}$. Compared to data in the literature the depth and width were not statistically significant from the average mean of world population. ${ }^{18}$ Konkani population has similar depth and width dimensions, while height dimension is statistically different from world average (at $\mathrm{p}$ value of $1.206 \times 10^{-20}<0.05$ ) as compared with world data in literature. Depth of right or left internal carotid artery from floor of the lateral pharyngeal recess was found to be $9.883 \pm 0.82 \mathrm{~mm}$ and $9.735 \pm 0.72 \mathrm{~mm}$ respectively. ${ }^{19}$ This study found that the average value of mucosal thickness was average $17.31 \pm 3.104 \mathrm{~mm}$ on the posterior wall of nasopharyngeal vault. It can be inferred that upper limit of mucosal thickening is $20.414 \mathrm{~mm}$ in the posterior pharyngeal wall as compared to previous literature values; any value beyond this is suspicious. ${ }^{20}$

\section{Clinical insights}

Internal carotid artery lies at the depth of around 1 to 1.7 $\mathrm{cm}$ from floor of lateral pharyngeal recess (fossa of Rosenmuller); this figure has to be borne in mind while doing invasive procedures of nasopharynx like biopsies and adenoidectomy. ${ }^{21}$ Posterior pharyngeal wall thickness of more than $2.4 \mathrm{~cm}$ and adenoid mass extending to posterior margin of the medial pterygoid plate is suspicious of malignancy. ${ }^{22}$

\section{CONCLUSION}

Posterior pharyngeal wall thickness of more than $2.4 \mathrm{~cm}$ and adenoid mass extending to posterior margin of the medial pterygoid plate is suspicious of malignancy. A screening protocol of CT nasopharynx has been suggested as a fruit of this endeavour.

\section{ACKNOWLEDGMENTS}

First author would like to thank his wife who helped with this research.

Funding: No funding sources

Conflict of interest: None declared

Ethical approval: The study was approved by the Institutional Ethics Committee

\section{REFERENCES}

1. Renko M, Kristo A, Tapiainen T, Koivunen P. Nasopharyngeal dimensions in magnetic resonance imaging and the risk of acute otitis media. J Otol Laryngol. 2017;121(9):853-6.

2. Ward FW, McNicholas WT. Clinical prediction of the sleep apnea syndrome. Sleep Med. 1997;1(1):19-32

3. Todd TW. Integral growth of pace: I. The nasal area. Am J Orthdontia Oral Surg. 1936;22(4):32134. 
4. Hairfield WM, Warren DW. Dimensions of the cleft nasal airway in adults: a comparison with subjects without cleft. J Cleft Palate. 1989;1:9-13.

5. Bresolin D, Shapiro PA, Shapiro GG, Chapko MK, Dassel S. Mouth breathing in allergic children: its relationship to dentofacial development. Am J Orthod. 1983;83(4):334-40.

6. Fujioka M, Young LW, Girdany BR. Radiographic evaluation of adenoidal size in children: adenoidalnasopharyngeal ratio. Am J Roentgenol. 1979;133:401-4.

7. Teresi LM, Lufkin RB, Vinuela F. MR imaging of the nasopharynx and floor of the middle cranial fossa-part I: Normal anatomy. Radiology. 1987;164:811-6.

8. El-Anwar MW, Ali AH, Elnashar I, Elfiki IM, Ahmed AF, Abdulmonaem G. Normal Nasopharyngeal Measurement by Computed Tomography in Adult. J Craniofac Surg. 2017;28(4):395-8

9. Oon CL. Some sagittal measurements of neck in normal adults. Br J Radiool. 1964;1(37):674-7.

10. Øyvind H, Harper David AT, Ryan Paul D. PAST: Paleontological statistics software package for education and data analysis. Palaeontologia Electronica. 2001;4(1):9-10.

11. Mancuso AA, Bohman L, Hanafee W, Maxwell D. Computed Tomography of the Nasopharynx: Normal and Variants of Normal. Radiology. 1980;137:113-21.

12. Feinstein AR. Clinical epidemiology the architecture of clinical research. Philadelphia; Saunders publishers: 1985;10:111-45.

13. Teresi LM, Lufkin RB, Vinuela F. MR imaging of the nasopharynx and floor of the middle cranial fossa-part I: Normal anatomy. Radiology. 1987;164:811-6.

14. Chong VFH, Fan YF. Radiology of the nasopharynx: Pictorial essay. Aust Radiol. 2000;44:5-13.
15. Mancusco AA, Harnsberger HR, Muraki AS, Stevens MH. Computed tomography of cervical and retropharyngeal lymph nodes: Normal anatomy, variants of normal, and applications in staging head and neck cancer. Part I. Normal anatomy. Radiology. 1983;148:709-14.

16. Mukherji SK, Weissman JL, Holliday R. The pharynx. In Head and Neck Imaging;H, C, Ed.; Mosby: New York, 1996;6:437-488.

17. Bloch S, Danziger J. Radiological experience with nasopharyngeal masses. J South African Med. 1973;47:2380-3.

18. Dickson RI, Flores AD. Nasopharyngeal carcinoma:an evaluation of 134 patients treated between 1971-1980. Laryngoscope. 1985;95:27688.

19. Zeng Y. Seroepidemiological studies on nasopharyngealcarcinoma in China. Arch Cancer Res. 1985;44:121-38.

20. Woo J, Sham CL. Diagnosis of nasopharyngeal carcinoma. Ear Nose and Throat Journal. 1990;69:241-2.

21. Lam WW, King AD, Ahuja AT, Metreweli C. Imaging. In: vanHasselt CA, Gibb AG(eds). Nasopharyngeal carcinoma, 2nd edn. Hong Kong: Chinese University Press; 1999: 127-160.

22. Waldron J, Kreel L, Metreweli C, Woo JKS, Van Hasselt CA. Comparison of plain radiographs and computed tomographic scanning in nasopharyngeal carcinoma. Clin Radiol. 1992;45:404-6.

Cite this article as: Rajamani SK, Karodpati N, Mogre DA, Prashant R. Radiological profiles of nasopharyngeal anatomy as seen in computed tomography scans of normal patients undergoing brain scans for other neurological problems in Konkani population. Int $\mathrm{J}$ Otorhinolaryngol Head Neck Surg 2019;5:1489-95. 